Revista

\title{
Multi-Ensayos
}

Vol. 6, núm. 11

ISSN: 2412-3285

https://multiensayos.unan.edu.ni

DOI: https://doi.org/10.5377/multiensayos.v6i11.9289

\section{UNAN-Managua promoviendo el cuido de la madre tierra}

\section{UNAN-Managua promoting the care of the earth mother}

Tamara Iveth Pérez Rodríguez

Recibido: 20 de octubre de 2019. Aceptado: 14 de enero de 2020

\section{RESUMEN}

La Universidad Nacional Autónoma de Nicaragua UNAN-Managua, está encaminando esfuerzos en torno a la formación de profesionales integrales desde y con una concepción científico-humanista del mundo, en este sentido está fomentando el cuido y protección de la madre tierra que permitan apoyar y poner en valor acciones generadas ambiente saludable acorde con la ecología, como las establecidas en los Estatutos, Políticas, Objetivos de Desarrollo Sostenible y la Agenda 2030. La educación universitaria en valores promoverá un mundo más justo, equitativo, igualitario y sustentable.

Palabras claves: ambiente; madre tierra; Objetivos de Desarrollo Sostenible; Agenda 2030; UNANManagua.

\section{ABSTRACT}

The National Autonomous University of Nicaragua, UNAN-Managua, addresses the integral training of professionals from and with a scientific-humanist conception of the world. In this sense, it promotes the care and protection of Mother Earth that allow support and put in value actions generated healthy environment in line with ecologies, such as those established in the Statutes, Policies, Sustainable Development Goals, and the 2030 Agenda. Thus, university education will promote values and a more just, equitable, equal, and sustainable world.

Keywords: environment; mother earth; Sustainable Development Goals; 2030 Agenda; UNAN-Managua.

1 Docente UNAN-Managua/FAREM-Estelí. Correo electrónico: tperez@unan.edu.ni, ORCID: https://orcid.org/0000-0002-70390484 


\section{INTRODUCCIÓN}

La ecología no es un lujo de los ricos ni una preocupación solo de grupos ecologistas o de los Verdes con sus respectivos partidos. La cuestión ecológica remite a un nuevo nivel de la conciencia mundial: la importancia de la Tierra como un todo, el bien común como bien de las personas, de las sociedades y del conjunto de los seres de la naturaleza, el riesgo apocalíptico que pesa sobre todo lo creado. El ser humano puede ser tanto ángel de la guarda como satanás de la Tierra. La tierra sangra, especialmente en su ser más singular, el oprimido, el marginado y el excluido, pues todos ellos componen las grandes mayorías del planeta. A partir de ellos debemos pensar el equilibrio y el nuevo orden ecológico mundial (Boff L. , 2000, pág. 193)

Las sociedades en el mundo actual están avanzando desmesuradamente en diversos aspectos que no son amigables con el ambiente en que vivimos y nos nutrimos, nos alimentamos de los recursos naturales y ecológicos de la madre tierra, continuamente actividades que van dirigidas al desarrollo urbano, agrícola, industrial, tecnológico, destruyen la naturaleza con la explotación indiscriminada legal e ilegal, todo con un fin comercial que se siente en el planeta y lo cual hacen a través de sus aparatos de destrucción masiva, disfrazados sobrevivencia alimentaria ¿Pero quiénes están detrás de todo esto? Las grandes transaccionales controladas por los países capitalistas y sus programas que de manera consciente nos venden a través de la publicidad engañosa.

La respuesta y las inquietudes nacen al compartir y sentir el sufrimiento de la naturaleza, desde el corazón como dice Leonardo Boff: "Ese es el gran desafío del siglo XXI, que seamos completamente humanos, con el derecho de sentarnos todos a la mesa y de atender decentemente necesidades alimentarias" (Boff L., 2015, pág. 104), con lo aportado por Boff, es sorprendente que el corazón de la naturaleza está clamando por sus derechos, los humanos han provocado tanto daño sin antes pensar en las consecuencias a largo plazo que se están ocasionando en el entorno.

\section{DESARROLLO}

La Universidad Nacional Autónoma de Nicaragua UNAN-Managua, está encaminando esfuerzos en torno a la formación de profesionales integrales desde y con una concepción científico-humanista del mundo, capaces de interpretar los fenómenos sociales y naturales con sentido crítico, reflexivo y proyectivo para que contribuyan al desarrollo social, por medio de un modelo educativo centrado en las personas, así mismo con compromiso social, con valores éticos, morales, humanistas y en defensa del medio ambiente (UNAN-Managua, 2018, pág. 149).

El principal interés es comprender la relación de los seres humanos y la naturaleza desde un paradigma holístico y no fragmentado tal como nos habla (Bohm D. , 1987, pág. 152), "Porque, como ya sabemos, este modo de vivir nos ha abocado a la contaminación, a la destrucción del equilibrio de la naturaleza, a la superpoblación, al desorden económico y político del mundo entero y a la creación de un medio ambiente que no es física, ni mentalmente saludable para la mayoría de la gente que tiene que vivir en 
él" en este sentido la UNAN-Managua es sus estatutos, artículo 6. Principios Rectores, e) Principio de Responsabilidad Social e Institucional: La UNAN-Managua promueve una cultura de vida saludable de la comunidad universitaria, así como la mejora continua de las capacidades de sus recursos humanos, cuido y conservación del medio ambiente mediante la implementación de buenas prácticas ambientales de consumo, prestaciones de servicios a la comunidad y el desarrollo de la producción sostenible; j) Principio de Respeto al Medio Ambiente: Significa el fomento, mejoramiento, preservación y conservación del medio ambiente, el uso sostenible de los recursos naturales, consumo y producción responsable, así como el respeto a la madre tierra y la humanidad como un único sistema de componentes físicos, químicos y biológicos y humanos que propician la producción y reproducción de la vida como bien común supremo y universal de la tierra y la humanidad (UNAN-Managua, 2018, pág. 149).

Con base en lo anterior el abordaje de las problemáticas ambientales como fragmentación, deforestación, contaminación de agua, suelo, aire, aparición de nuevas plagas, sequía, inundaciones, calentamiento global entre muchos otros, se deben tratar desde un enfoque holístico e integrador en las diversas asignaturas de las carreras que se ofertan en la UNAN-Managua, ya que afecta nuestra salud, economía, relaciones políticas, las relaciones intelectuales, espirituales y morales. Empédocles atribuía los cambios en el universo al flujo y reflujo de dos fuerzas complementarias que llamaba amor y odio (Capra, 1992, pág. 247), esto nos lleva a tener amor por nuestra especie y más aún por nuestro planeta y el universo, invita a poner más atención en las relaciones interpersonales y con nuestro entorno, donde transmitiremos la semilla del amor por la madre tierra.

Desde la Política de Extensión Universitaria se retoma el componente ambiental como uno de los principales ejes de acción que permitan consolidar en el ámbito universitario acciones de gestión ambiental mediante mecanismos de desarrollo limpio como manejo de los residuos sólidos y líquidos, comunes y peligrosos, uso y consumo responsable de agua; ahorro de energía, conservación de áreas verdes y de ambientes libres de humo de tabaco, así como regulación para casos de emergencias y desastres (UNAN-Managua, 2017, pág. 27).

Para dar cumplimiento a lo anterior se han venido realizando una serie de actividades orientadas a la conservación ambiental como reforestación en las Facultades, Politécnico de la Salud Luis Felipe Moncada, Centros de Investigación, Economía, Laboratorio de Biotecnología, Facultades Regionales Multidisciplinarias de Estelí, Matagalpa, Carazo y Chontales, jornadas de limpieza, elaboración de murales informativos y alusivos a efemérides ambientales, charlas de sensibilización, participación en ferias ambientales, reciclatón, jornadas de reforestación, establecimiento de viveros de plantas medicinales, elaboración de trípticos con temáticas ambientales, participación en programas radiales en saludo al 05 de junio día internacional del Medio Ambiente, entre otras. Así como giras a zonas protegidas y parques nacionales, que promuevan el aprendizaje a partir de la convivencia en el medio ambiente natural que es parte de la riqueza de nuestro país.

La UNAN-Managua es una institución de Educación Superior, Pública y Autónoma, de referencia nacional e internacional en la formación de profesionales comprometidos con la conservación de nuestros recursos 
naturales, es menester nuestro trabajar de acuerdo a los lineamientos de gobierno y abonar a esa ardua labor de dar cumplimiento de los Objetivos de Desarrollo Sostenible (ODS).

De acuerdo con lo establecido en la Agenda 2030 para el Desarrollo Sostenible, en función de esto estamos actualizando la Política Ambiental Institucional que nos dará las pautas para trabajar en función del cumplimiento de los ODS, tenemos como institución académica de aportar por medio de investigaciones, prácticas y proyectos a la conservación de nuestro ambiente, promoviendo la cultura de respeto a la biodiversidad, la flora y fauna que se encuentra en las instalaciones de nuestra alma mater, la manejo integrado de cuencas hidrográficas, a la reducción de las vulnerabilidades que permitan gestionar los riesgos naturales y antrópicos, así mismo los efectos del cambio climático, todo esto se debe implementar de manera transversal en los planes y programas académicos que contribuyan a la transformación social de la comunidad universitaria y la población Nicaragüense.

Con este fin estamos creando alianzas estratégicas con instituciones gubernamentales y no gubernamentales, empresas privadas, organizaciones y movimientos ambientalistas, que nos permitan el fortalecimiento de las acciones encaminadas a mejorar la calidad ambiental del campus universitario y por ende la a mejorar la calidad de vida de la comunidad universitaria.

En la conferencia regional de educación superior en América Latina y el Caribe (CRES 2018) se reafirmó el compromiso de la región con un mundo más justo, equitativo, igualitario y sustentable, en este sentido consolidar la educación superior en nuestro país será el motor principal para transformar nuestra comunidad universitaria y extensivo a nuestra sociedad atendiendo de esta forma los Objetivos de Desarrollo Sostenible y la Agenda de Educación 2030 asumiendo el compromiso para contribuir al fomento de la protección del planeta y todas las formas de vida.

En caminados a dar cumplimiento al compromiso que tenemos como casa de estudio de educación superior tenemos nuestra Política Ambiental Institucional de la UNAN-Managua, que contempla ejes temáticos y acciones estratégicos tales como; Plan de Gestión Ambiental y Manejo Integral de los Residuos Sólidos, Plan de Gestión Ambiental y Manejo de los Residuos Sólidos Peligrosos, Cultura de Cuido y de Respeto a la Biodiversidad, La Flora y La Fauna que se encuentra en los Campus Universitarios, Manejo Integral de Cuencas Hidrográficas y Recursos Hídricos, Gestión Integral para la Reducción del Riesgo a Desastres y Adaptación al Cambio Climático, Desarrollo Sostenible en todo los Procesos, Actividades y Funciones Universitaria, Control Ambiental y Sanitario en la Manipulación de Alimentos, Recepción, Procesamiento, Almacenamiento, Trasporte y Comercialización, Educación Ambiental Universitaria, en todos los Planes y Programas de la Educación Superior que Contribuya a la Transformación Social de la Comunidad Universitaria y la Población Nicaragüense, Información, Comunicación y Divulgación Ambiental, con estos ejes temáticos desarrollaremos acciones encaminadas a mejorar la calidad de vida de nuestra comunidad universitaria y su entorno cercano.

La unidad para actuar juntos y juntas en acciones nos conllevará a buscar soluciones para la restauración y cuido de nuestra casa común, nuestra tierra, debemos profundizar en un modelo donde el pensamiento 
humano basado en valores, se una al sentimiento de amor ancestral y su sabiduría. Así mismo fortalecer las alianzas estratégicas inter e intra institucionales para el desarrollo de la ciencia, tecnología y comercialización a partir de las ideas innovadoras y de emprendimientos ambientales de los estudiantes y docentes, permitiendo impulsar acciones que reflejen el cuido y conservación de nuestra madre tierra, esto es un reto que debemos asumir a diario desde nuestros hogares, escuelas y universidades, por lo que se sugiere incorporarlo en el Plan Operativo Anual Institucional.

En cuanto a las investigaciones tenemos un compromiso importante como docentes investigadores, de proponer alternativas a los problemas que aquejan a nuestra sociedad, en función a esto se está desarrollando un proceso de investigaciones sobre microplásticos en los océanos, reutilización de aceite usado de cocina, resiliencia comunitaria de pequeños productores agrícolas al fenómeno de la sequía

En el corredor seco de Nicaragua: un análisis sociocultural e institucional desde una perspectiva histórica, evaluación del potencial de almacenamiento de carbono aéreo de remanentes de bosques tropicales húmedos en el Paisaje Terrestre Protegido Miraflor-Moropotente, Estructura, diversidad y valor de importancia para la conservación de los remanentes de bosque de trópico seco en la zona Norcentral de Nicaragua, Aseguramiento de la calidad en las mediciones requeridas para la determinación de la biodegradabilidad de sustancias químicas, Estudios de líneas de base de residuos de plaguicidas en vegetales de alto consumo provenientes de zonas hortícolas de Nicaragua y comercializados en Managua.

Desde la UNAN-Managua se está contribuyendo al intercambio local con acciones que permiten fomentar el conocimiento sobre las innovaciones en la gestión del ambiente y los recursos naturales, y a la consecución de un crecimiento sostenible e incluyente, motivada a involucrarse de forma tangible y aplicada en la generación de información y conocimientos para el monitoreo de las áreas protegidas, los bosques naturales, la calidad del agua, así como de la biodiversidad nacional.

\section{CONCLUSIÓN}

Es necesario fomentar una cultura en la comunidad universitaria de respeto y sostenibilidad ambiental, la cual debe involucrar el sistema de educación, campañas de sensibilización a nivel nacional que promuevan valores ambientales enfocados a la conservación de nuestro patrimonio natural nacional, nuestra madre tierra.

Es menester de nuestra máxima casa de estudio el dar cumplimiento a las políticas institucionales y nacionales en materia ambiental, con un mundo más justo, equitativo, igualitario y sustentable, consolidando la educación superior siendo este el motor principal para transformar nuestra comunidad universitaria. 


\section{REFERENCIAS}

Boff, L. (2000). La Dignidad de la tierra, ecología, mundialización, espiritualidad, le emergencia de un nuevo paradigma. Madrid: Trotta S.A.

Boff, L. (2015). Derechos del corazón. Una Inteligencia cordial. Madrid: Trotta S.A.

Bohm, D. (1987). La totalidad y el orden implicado. Barcelona : Kairós S.A.

Capra, F. (1992). El punto crucial. Ciencia, sociedad y cultura naciente. Buenos Aires: Troquel S.A .

UNAN-Managua. (2017). Politica de extensión Universitaria 2017-2019. Managua: Universitaria UNANManagua.

UNAN-Managua. (2018). Estatutos de la UNAN-Managua con su reforma. Managua: Universitaria UNANManagua. 